\title{
A Compact High Gain Printed Antenna with Frequency Selective Surface for 5G Wideband Applications
}

\author{
Ankush Kapoor1,2, Ranjan Mishra1, Pradeep Kumar³ \\ ${ }^{1}$ Department of Electrical and Electronics Engineering, \\ University of Petroleum and Energy Studies, Dehradun, India \\ ${ }^{2}$ Department of Electronics and Communication Engineering, \\ Jawaharlal Nehru Government Engineering College, Sundernagar, Mandi, India \\ ${ }^{3}$ Discipiline of Electrical, Electronic and Computer Engineering, \\ University of KwaZulu-Natal, Durban-4041, South Africa \\ Corresponding author: Ankush Kapoor (e-mail: ankush8818@yahoo.com).
}

\begin{abstract}
This paper reports on the development of a compact wideband printed antenna radiator with improved gain and directivity by making use of frequency selective surfaces (FSSs). The proposed design is meant to be operated in the $\mathrm{n} 77$ and $\mathrm{n} 78$ bands of the sub- $6 \mathrm{GHz} 5 \mathrm{G}$ allocated apectrum. In today's era of advanced technology, compact antennas with high gain and high directivity are required for wireless applications. FSS based spatial filters are attracting the interest of researchers due to their capability to pass only selective radiations while avoiding unwanted frequencies. The composition of architecture equations for designing the band pass FSS using double square loop geometry and printed patch antenna radiator are presented in this article. The geometries of FSS and printed patch antenna radiator (PAR) are designed for operation in targeted $n 77$ and $n 78$ bands in the sub- 6 GHz $5 \mathrm{G}$ spectrum. The designs of PAR and a double square loop FSS (DSLFSS) are integrated together. The simulations are performed using the ANSYS HFSS software. The prototype is fabricated, and the results are verified using the measuring setup. The fractional bandwith of the antenna is $19.14 \%$ with the peak gain of $5.5 \mathrm{dBi}$ gain and peak directivity of $6.2 \mathrm{dBi}$. The uniqueness of the proposed design lies in the achievement of a compact size, low cost as antenna and DSLFSS are fabricated on the low cost FR4 substrate, high gain, high directivity and wide bandwidth, which make the proposed antenna a good choice for $5 \mathrm{G}$ wideband applications.
\end{abstract}

INDEX TERMS Patch Antenna Radiator (PAR), Double Square Loop Frequency Selective Surface (DSLFSS), Partial Slotted Ground Rectangular Patch Antenna (PSGRPA), Flame Retardant 4 (FR4).

\section{INTRODUCTION}

An enormous number of wireless activated electronic devices such as smartphones, tablets and notebooks have been in demand throughout the last decade. The adoption of more modern wireless devices has propelled enhancing the performance of the antenna radiators in terms of bandwidth and gain. Patch antenna radiators (PAR) have made an enormous advancement in recent years because of their additional benefits and better prospects as compared to the traditionally prepared antenna radiators [1]. They are marginally thinner and lighter, shorter in length, cheaper in expense, narrower in scale, and easier in fabrication. Furthermore, these exhibit an added advantage of possessing dual and circular polarizations, multi-frequency operations, broad bandwidth, feed line mobility and omnidirectional scanning. These advantages are catered by proposing a new design of PAR's. Exponential growth is visualized in usage of smart phones and it is projected that data traffic will be increased by ten times over the coming decade. The target of future wireless communication is for achieving a super-fast transmission rate (maximum data rate $\geq 10 \mathrm{Gbps})$, low latency $(\leq 1 \mathrm{~ms})$, extreme dense connections and higher mobility $(\geq 800 \mathrm{~km} / \mathrm{h})$. The solution was achieved to an extent by the deployment of $5 \mathrm{G}$ wireless technology [2]. ITU has divided the key spectrum of $5 \mathrm{G}$ into low-band (up to $1 \mathrm{GHz}$ ), mid-band (sub-6 GHz), and high-band (mmWave) [3]-[5]. In the mmWave band, the faster data rates with a large capacity are achieved, while the low band offers good coverage, and in the midband, we get a blend of both capacity and coverage. So, the right choice for ready-to-go technology for getting implemented at first instance is sub-6 GHz $5 \mathrm{G}$ frequency band. As the range of the allocated frequencies for the sub$6 \mathrm{GHz} 5 \mathrm{G}$ bands enables to convey high data rates over long distances, it makes this suitable for usage in both urban and rural areas. The antennae form an integral part of all wireless communication systems. As the world has welcomed the $5 \mathrm{G}$ communication system with all grace, so 
antenna design for 5G base stations and smart devices is in great demand. The range of the allocated frequency spectrum offers enormous challenges for antenna designing for $5 \mathrm{G}$ communication system. The design of the antenna radiator for operation in the $5 \mathrm{G}$ range should be compact enough to be integrated internally with portable devices. Also, the antenna designed in the sub- $6 \mathrm{GHz}$ frequency range must be able to operate along with the existing Long Term Evolution (LTE) and other operable service bands of 4G technology. Adequate numbers of antennae are already proposed for 5G communication applications [6] and [7]. PAR's are a common choice to be used in sub- $6 \mathrm{GHz}$ frequency ranges as they exhibit advantages such as compact dimensions, cheaper cost, and possess broader bandwidth [8]. Nevertheless, a major disadvantage of using these antenna radiators is that when they are mounted near metallic objects and electromagnetic devices then they suffer from an acute mismatch in impedance. Another drawback is in the form of poor gain and weaker directivity as seen at lower frequencies in the microwave spectrum. In this article, a method is devised to enhance the performance of the PAR by incorporating a layer of frequency selective surface (FSS) which acts as a spatial filter when placed in an environment of electromagnetic radiation which is illustrated in Figure 1. When enclosed with radiofrequency electromagnetic radiation, FSS's act as periodic arrays of conductive elements which allows a specific set of frequencies to pass through while reflect the other set of frequencies.

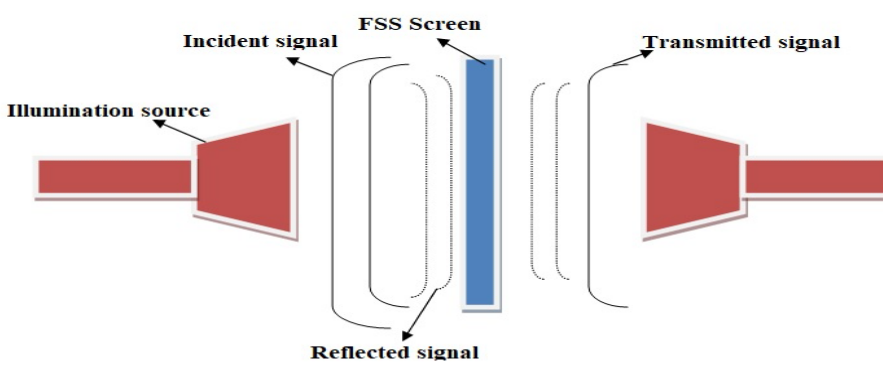

FIGURE 1:. FSS surface as a spatial filter.

Element geometry orientation, spacing between elements, substrate properties (such as permittivity, loss tangent and thickness) and the surrounding environment are the factors that alter the frequency response of the FSS [8]. High frequency spatial filters [9]-[10], reflectors [8], lenses [11], radomes [12]-[13], and absorbers [14]-[17] are some of the applications in which FSS has been used throughout the past. Recently with an increase in demand for sensors, FSS are often used for systemic health monitoring (SHM) purposes [18]-[19]. Many structures consisting of a compact single layer FSS with metallic screens while $2.5 \mathrm{D}$ Jerusalem cross FSS geometry for applications in 5G radomes is presented [20]-[21]. Many studies have been conducted for implementing stacked geometries consisting of a layer of FSS with PAR meant for enhancing the radiation characteristics [22]-[32]. FSS, when constructed properly may act as a spatial filter for the plane waves and finds its applications in broadband communications, radar systems, and for high performance applications. It created our interest in designing and performing numerical synthesis for the stacked layer design of the PAR with FSS for implementation in then 77 and $n 78$ bands of the sub- 6 $\mathrm{GHz} 5 \mathrm{G}$ devices. In this manuscript, we have described a method for increasing the gain and directivity of a patch antenna radiator along with enhancing the bandwidth by using FSS. Initially, a conventional patch antenna radiator is designed in the $n 77$ and $n 78$ bands of the sub- $6 \mathrm{GHz} 5 \mathrm{G}$ spectrum. The bandwidth of operation is enhanced by incorporating the concept of defected ground substrate. The physical size of the ground plane is reduced to half in dimension along major axis and a slot is carved on the ground plane. The polygon shaped slot structure consisting of 20 (twenty) segments is carved on the ground plane. The methodology of this design is described in the coming section of this article. After a thorough analysis, we discovered that loading a microstrip antenna with slots in the ground plane allows us to achieve a wider bandwidth. Implementation of slotted ground plane has an added benefit of attaining a simpler architecture by reducing the overall dimensions and thus making it possible to be embedded inside the printed circuit boards. The partial slotted ground rectangular patch antenna (PSGRPA) is implemented on the FR4 substrate. The measurements reported that the bandwidth is increased at the cost of a decrease in antenna gain and directivity. To overcome these limitations a frequency selective surface is incorporated along with PAR in a stacked geometry. The reported results make it a good choice to enhance the performance of the PAR in terms of gain, directivity and bandwidth.

The successive structure of the paper is oriented by describing the synthesis technique of DSLFSS in section II. The DSLFSS based antenna design, antenna geometry, simulated and measured results are presented in section III. Section IV gives the conclusion of the work.

\section{SUPERSTRATE DSLFSS GEOMETRY}

Frequency selective surfaces (FSS) when constructed properly can be an asset in boosting up the gain and directivity of the printed patch radiator as well as it can provide shielding to the electronic circuit lying below the surface. FSS possesses the inherent property of decoupling the patch radiator and surrounding metallic devices. It allows the manufacturer to place the patch radiator close to the nearby metallic surface, and in return, it increases the overall system compactness. The FSS is often referred to as spatial filters which consist of repetitive structures built by a pre-designed unit cell repetition. Based on their particular unit cell configuration, operational frequency and polarization of the incoming electromagnetic wave, FSS serve as spatial filters. They can be configured to enable electromagnetic waves to move through them (band pass FSS) or mirror them (band stop FSS). Furthermore, the phase of the reflected wave can be regulated by the usage of FSS to ensure constructive interference. This segment introduces the FSS double square loop 
configuration. The design methodology opted in this paper consists of double square periodic surface structures having an added advantage of being angular independent with simplicity in the design. For analyzing and formulating the FSS design, the analogous circuit model approach is used. The simple geometric requirements of the unit cell portion of the proposed double square loop frequency selective surface (DSLFSS) architecture is illustrated and depicted in Figure 2(a). It provides a strong band pass response making it an ideal choice for use as a superstrate in the desired sub- $6 \mathrm{GHz} 5 \mathrm{G}$ spectrum. It is very important to analyze the unit cell portion of DSLFSS as per the Floquet theory because the field characteristics of the designed FSS array are same as that of a single unit cell element [33]. The equivalent circuit analysis is carried out by the equations described for the periodic gratings as given by Marcuvitz [34]. The relation of the dimensions of the DSLFSS structure with the lumped circuit elements is being utilized. The parameters, such as capacitance and inductance, are extracted from the geometry of the FSS structure. It utilizes the values of the dimensions such as arm side of square loop (s), unit cell periodicity (p), thickness of the conducting strip $(\mathrm{t})$, angle of incidence $(\theta$ for TE and $\phi$ for TM), wavelength of the ray striking the surface $(\lambda)$ and the distance between the adjacent loop configuration (d). The schematic representation of the DSLFSS, as depicted in Figure 2(a), is consisting of a copper sheet of thickness of $0.02 \mathrm{~mm}$ from which a double square loop structure is configured and substituted on FR4 substrate of height $(\mathrm{h})$ of $1.6 \mathrm{~mm}$. The DSLFSS acts as a band-pass filter and is used as a superstrate along with the patch antenna radiator to increase its performance characteristics. As the out-of-band radiations are emitted from the surface of the patch antenna radiator, it enhances its overall performance and an increase in the value of gain and directivity while maintaining the wide bandwidth performance and compact dimensions. The superstrate structure is depicted in Figure 2(b). However, to construct the DSLFSS configuration it is necessary to formulate the dimensions of the loops along with periodicity of the unit cell structure, for which it is required for getting the band pass behavior of the structure with the considerable broader bandwidth. The designed DSLFSS must be able to pass the frequencies in between the range at which proposed designed PSGRPA radiates. The band pass DSLFSS is substituted as a superstrate upon the antenna. In the literature, an effective synthesis technique has been documented as seen in [35] and [36], which formed the basis for our precise mathematical analysis via an equivalent circuit model method.

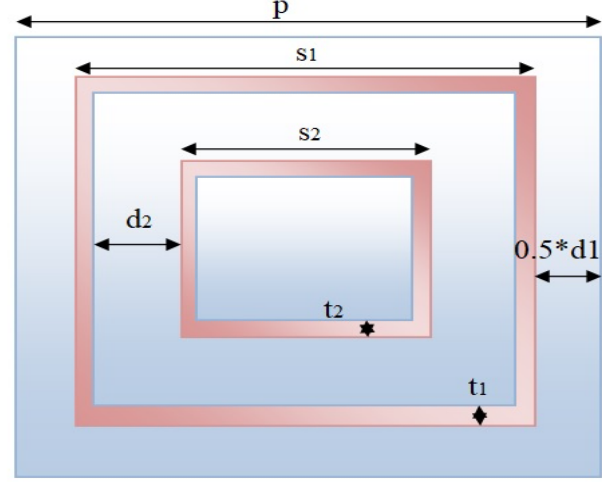

(a)

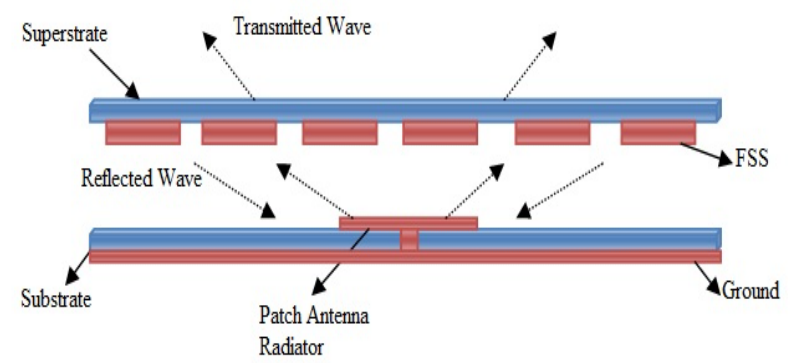

(b)

FIGURE 2:.DSLFSS unit cell and DSLFSS as a superstrate on the proposed PSGRPA (a) schematic of the DSLFSS unit cell, and (b) DSLFSS as a superstrate on the proposed PSGRPA.

The dimensions of the lumped circuit elements are extracted from the equivalent circuit model synthesis and further, these depend upon values of periodicity (p), thickness of the square loop (t), angle of incidence $(\theta, \phi)$ and also on the mode of incidence whether it is transverse electric (TE) or transverse magnetic (TM). Considering firstly TE mode of incidence which when incident on the surface of the FSS illuminates the structure and the lumped circuit elements for each square loop geometry can be calculated as:

$\frac{\omega_{\mathrm{r}} \mathrm{L}}{\mathrm{Z}_{0}}=\frac{\mathrm{s}}{\mathrm{p}} \cos \theta * \mathrm{~F}(\mathrm{p}, \mathrm{t}, \lambda, \theta)$

$\mathrm{F}(\mathrm{p}, \mathrm{t}, \lambda, \theta)=\frac{\mathrm{p}}{\lambda}\left[\ln \csc \left(\frac{\pi \mathrm{t}}{2 \mathrm{p}}\right)+\mathrm{G}(\mathrm{p}, \mathrm{t}, \lambda, \theta)\right]$

Also, $\frac{\omega_{\mathrm{r}} \mathrm{C}}{\mathrm{Y}_{0}}=4 \frac{\mathrm{s}}{\mathrm{p}} \sec \theta * \mathrm{~F}(\mathrm{p}, \mathrm{d}, \lambda, \theta) * \varepsilon_{\text {eff }}$

where $\varepsilon_{\text {eff }}$ denotes the effective permittivity of the surface and 'csc' is termed for cosecant of an angle.

$\mathrm{F}(\mathrm{p}, \mathrm{d}, \lambda, \theta)=\frac{\mathrm{p}}{\lambda}\left[\ln \csc \left(\frac{\pi \mathrm{d}}{2 \mathrm{p}}\right)+\mathrm{G}(\mathrm{p}, \mathrm{d}, \lambda, \theta)\right]$

The terms $\varepsilon_{\text {eff }}, Z_{0}, Y_{0}, G(p, t, \lambda, \theta)$ and $G(p, d, \lambda, \theta)$ denote the effective dielectric permittivity of the DSLFSS, value of the characteristic impedance, value of the characteristic admittance and the terms added to remove the errors in the calculation of the inductance and capacitance of the engineered FSS surface. Further in [37], some generalized expressions for the terms associated to remove errors with (1) to (4) were elaborated and described as:

Mathematical extraction of the first order correction term $\mathrm{G}()$ was given as:

$\mathrm{G}(\mathrm{p}, \mathrm{t}, \lambda, \theta)$ or $\mathrm{G}(\mathrm{p}, \mathrm{d}, \lambda, \theta)=\frac{\mathrm{E}}{\mathrm{F}}$

where 


$$
\begin{aligned}
& \mathrm{E}=0.5\left(1-\Gamma^{2}\right)^{2}\left[\left(1-\frac{\Gamma^{2}}{4}\right)\left(\mathrm{C}_{+1}+\mathrm{C}_{-1}\right)+4 \Gamma^{2} \mathrm{C}_{+1} \mathrm{C}_{-1}\right] \\
& \mathrm{F}=\left(1-\frac{\Gamma^{2}}{4}\right)+\Gamma^{2}\left(1+\frac{\Gamma^{2}}{2}-\frac{\Gamma^{4}}{8}\right)\left(\mathrm{C}_{+1}+\mathrm{C}_{-1}\right)+ \\
& 2 \Gamma^{6} \mathrm{C}_{+1} \mathrm{C}_{-1} \\
& \quad \text { where } \Gamma=\frac{\sin \pi t}{2 p} .
\end{aligned}
$$

The coefficients of the first order are calculated as:

$\mathrm{C}_{\mathrm{n}}=\frac{1}{\mathrm{hS}_{\mathrm{n}}}-\frac{1}{\bmod \mathrm{n}}$ where $\mathrm{n}= \pm 1, \pm 2, \ldots \ldots$

For TE incident ray $S_{n} h=\sqrt{\left(\frac{p \sin \theta}{\lambda} \pm n\right)^{2}-\frac{p^{2}}{\lambda^{2}}}$

For TM incident ray $S_{n} h=\sqrt{\left(\frac{p \sin \Phi}{\lambda}\right)^{2}+n^{2}-\frac{p^{2}}{\lambda^{2}}}$

To get our design formulated we proceed with ignoring the correction factor term at the cost of slight deviations in our end results as shown in (11) and (12) respectively.

$\frac{\omega_{\mathrm{r}} \mathrm{L}}{\mathrm{z}_{0}}=\frac{\mathrm{s}}{\mathrm{p}} \cos \theta * \frac{\mathrm{p}}{\lambda} \ln \left[\csc \left(\frac{\pi \mathrm{t}}{2 \mathrm{p}}\right)\right]$

$\frac{\omega_{\mathrm{r}} \mathrm{C}}{\mathrm{Y}_{0}}=4 \frac{\mathrm{s}}{\mathrm{p}} \sec \theta * \frac{\mathrm{p}}{\lambda} \ln \left[\csc \left(\frac{\pi \mathrm{d}}{2 \mathrm{p}}\right)\right] * \varepsilon_{\mathrm{eff}}$

In the above equation it is to be taken into account that the equations (11) and (12) are valid only if we have $t<<$, s $<<\mathrm{p}$, and $\mathrm{p}<<\lambda$. Now, let us consider the air as a substrate and on multiplying (11) and (12) we get:

$\omega_{\mathrm{r}}^{2} \mathrm{LC}=4\left(\frac{\mathrm{s}}{\mathrm{p}}\right)^{2}\left(\frac{\mathrm{p}}{\lambda}\right)^{2} * \ln \left[\csc \left(\frac{\pi \mathrm{t}}{2 \mathrm{p}}\right)+\csc \left(\frac{\pi \mathrm{d}}{2 \mathrm{p}}\right)\right]$

On visualizing equation (13), it is visible that the lefthand side of the equation is exhibiting resonance criteria which are a measurement of the quality factor. Considering a special case of fully reflective DSLFSS, the value of lefthand side of the equation must be equal to 1 and it happens when $\omega_{\mathrm{r}}^{2}=\frac{1}{\mathrm{LC}}$.

So, rewriting equation (13), we get:

$1=4\left(\frac{\mathrm{s}}{\mathrm{p}}\right)^{2}\left(\frac{\mathrm{p}}{\lambda}\right)^{2} * \ln \left[\csc \left(\frac{\pi \mathrm{t}}{2 \mathrm{p}}\right)+\csc \left(\frac{\pi \mathrm{d}}{2 \mathrm{p}}\right)\right]$

Simplifying equation (14), we get:

$1=4\left(\frac{\mathrm{s}}{\mathrm{p}}\right)^{2}\left(\frac{\mathrm{p}}{\lambda}\right)^{2} * \ln \left[\frac{1}{\sin \left(\frac{\pi \mathrm{t}}{2 \mathrm{p}}\right)}+\frac{1}{\sin \left(\frac{\pi \mathrm{d}}{2 \mathrm{p}}\right)}\right]$

While opting for a special criterion in which we assume $\mathrm{t}$ $<<2$ p and $\mathrm{d}<<2$ p we get:

$1=4\left(\frac{s}{p}\right)^{2}\left(\frac{p}{\lambda}\right)^{2} * \ln \left[\left(\frac{2 p}{\pi t}\right)+\left(\frac{2 p}{\pi d}\right)\right]$

As the desired frequency band of operation lies in the sub$6 \mathrm{GHz} 5 \mathrm{G}$ spectrums, so while designing the DSLFSS surface, an assumption is taken stating that the value of $d$ must be greater than the value of $t$ making the ratio $\left(\frac{2 p}{\pi t}\right)$ greater then $\left(\frac{2 p}{\pi d}\right)$. Hence, (16) may be rewritten as:

$1=4\left(\frac{s}{\lambda}\right)^{2} * \ln \left[\left(\frac{2 p}{\pi t}\right)\right]$

It is an inherent property of FSS by virtue of which the incidence angle $(\theta)$ and periodicity affect the performance of band-pass behavior. The expression for relating periodicity with angle of incidence and wavelength is given as [22]:

$\mathrm{p}(1+\sin \theta)<\lambda$

After simplification and taking appropriate assumptions, a generalized expression is given as:
$\mathrm{p}=\mathrm{M} \lambda$

where $\mathrm{M}$ is the constant of proportionality, and its value lies in between 0 and 1 .

On substituting (19) in (17), we get

$1=4\left(\frac{\mathrm{s}}{\lambda}\right)^{2} * \ln \left[\left(\frac{2 \mathrm{M} \lambda}{\pi \mathrm{t}}\right)\right]$

The square loop dimensions can be extracted and optimized using equations (18) and (20). The abovementioned analysis is provided for TE mode and the same expressions are also valid for TM mode due to polarization independent behavior property of square loop FSS. The equivalent circuit of a DSLFSS, as a combination of inductance (L) and capacitance $(\mathrm{C})$ is illustrated in Figure 3 , and it acts as an LC filter.

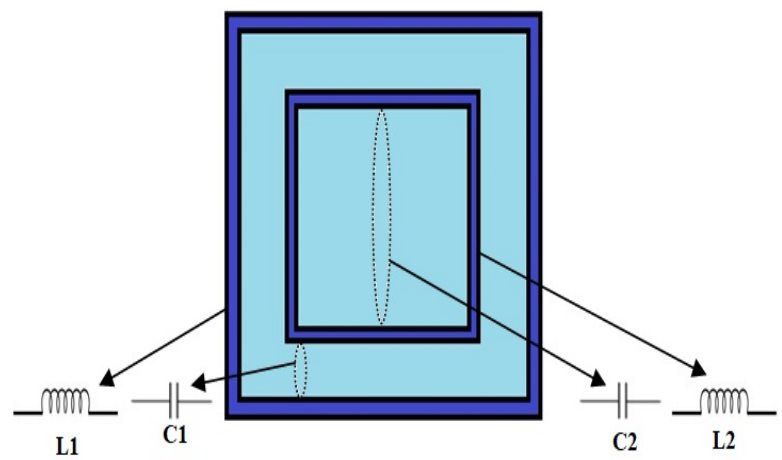

(a)

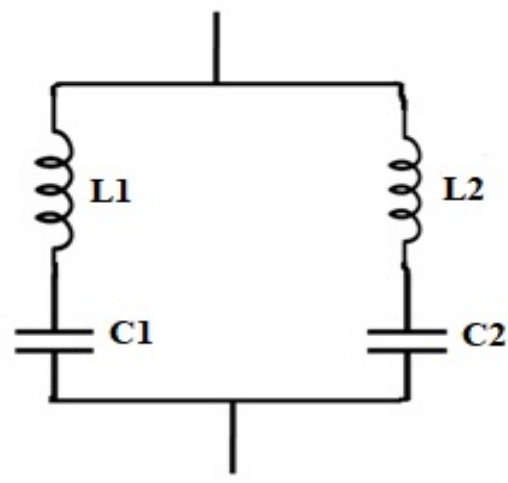

(b)

FIGURE 3:.DSLFSS lumped circuit elements and equivalent circuit (a) DSLFSS with lumped circuit elements, and (b) Equivalent Circuit of single unit cell FSS.

The hypothesis provided above is utilized to identify the physical dimensions of the square loop structure in the spectrum of sub-6 GHz FR1 frequency range. The parameters when incorporated in the equations described from equation (1) to equation (20) as described are able to extract the dimensions of the physical parameters and give us adequate results for the DSLFSS structure exhibiting band pass behaviour. Verification of the operating frequency bands is obtained by substituting the values of the lumped circuit elements evaluated in the expression of the resonance frequency obtained for the spatial LC filters as:

$$
\begin{aligned}
\mathrm{f}_{\mathrm{r}_{1}} & =\frac{1}{2 \pi \sqrt{\mathrm{L}_{1} \mathrm{C}_{1}}} \\
\mathrm{f}_{\mathrm{r}_{2}} & =\frac{1}{2 \pi \sqrt{\mathrm{L}_{2} \mathrm{C}_{2}}}
\end{aligned}
$$


It is important to extract the value of the periodicity for designing the band pass spatial filters using FSS structure. Its value is determined by satisfying the equation (18) at normal angle of incidence (AOI) of $0^{0}$ and for lower resonant frequency of $3.3 \mathrm{GHz}$. With these two stated values, (18) reduces to:

$\mathrm{p}<\lambda ; \mathrm{p} \approx \frac{\lambda}{2.25}$ for outer loop (in $\mathrm{n} 77$ and $\mathrm{n} 78$ band in sub-6 GHz FR1)

Also, retrieving information from the equation (19), a dedicated expression can be defined for the outer square loop design in the sub- $6 \mathrm{GHz}$ range as:

$\mathrm{p} \approx 0.44 \lambda$ for outer loop (in $\mathrm{n} 77$ and $\mathrm{n} 78$ band in sub- 6 GHz FR1)

Thereafter on fixing the value of $M$, we proceed for evaluating the dimensions of the outer loop arm length and thickness. Now, again considering the inner loop parameters, the higher resonant frequency is significant at $5.81 \mathrm{GHz}$ and for AOI of $0^{\circ}$, and with these values (18) reduces to:

$\mathrm{p}<\lambda ; \mathrm{p} \approx \frac{\lambda}{1.29}$ for inner loop (in $\mathrm{n} 77$ and $\mathrm{n} 78$ band in sub-6 GHz FR1)

Further, the dedicated expression for the inner square loop in the sub- $6 \mathrm{GHz}$ range from equation (19) is retrieved as: $\mathrm{p} \approx 0.77 \lambda$ for inner loop (in $\mathrm{n} 77$ and $\mathrm{n} 78$ band in sub- 6 GHz FR1)

The synthesis technique described gives the equivalent circuit parameters such as inductance and capacitance as depicted in Figure 3(b). Equations (1) and (3) are used to find out approximate values for the lumped circuit elements from the dimensions of the loops and vice versa. The final design values extracted from the hypothesis in the sub-6 GHz FR1 spectrum are given in Table I.

TABLE I. Parameters of DSLFSS in sub- $6 \mathrm{GHz}$ range.

\begin{tabular}{cc}
\hline \hline Parameter & Value \\
\hline Lower resonant frequency $\mathrm{f}_{\mathrm{r} 1}(\mathrm{GHz})$ & 3.32 \\
Lumped circuit parameters & 5.82 \\
Higher cut off frequency $\mathrm{f}_{\mathrm{r} 2}(\mathrm{GHz})$ & 3.678 \\
Outer loop inductance $\mathrm{L}_{1}(\mathrm{nH})$ & 12.453 \\
Inner loop inductance $\mathrm{L}_{2}(\mathrm{nH})$ & 0.632 \\
Capacitance due to outer loop $\mathrm{C}_{1}(\mathrm{pF})$ & 0.060 \\
Capacitance due to inner loop $\mathrm{C}_{2}(\mathrm{pF})$ & \\
Physical dimensions & $0.6 \lambda_{\text {mid }}$ \\
Periodicity p & $0.07 \lambda_{\text {mid }}$ \\
Width of outer loop $\mathrm{t}_{1}$ & $0.45 \lambda_{\text {mid }}$ \\
Arm length of outer loop $\mathrm{s}_{1}$ & $0.06 \lambda_{\text {mid }}$ \\
Width of inner loop $\mathrm{t}_{2}$ &
\end{tabular}

where $\lambda_{\text {mid }}$ is the middle frequency wavelength within the operating band of $3.32 \mathrm{GHz}-5.82 \mathrm{GHz}$.

It is indicated by the DSLFSS frequency response model that the transmission coefficient $\left(\mathrm{S}_{21}\right)$ attains a minimum value at the two resonance frequencies ( $f_{r 1}$ and $f_{r 2}$ ) as shown in Figure 4. The values of the resonant frequencies are indicated and regulated by external and internal loops in such a manner that the inner resonant frequency is expressed by the outer loop and the outer resonant frequency is represented by the inner loop.

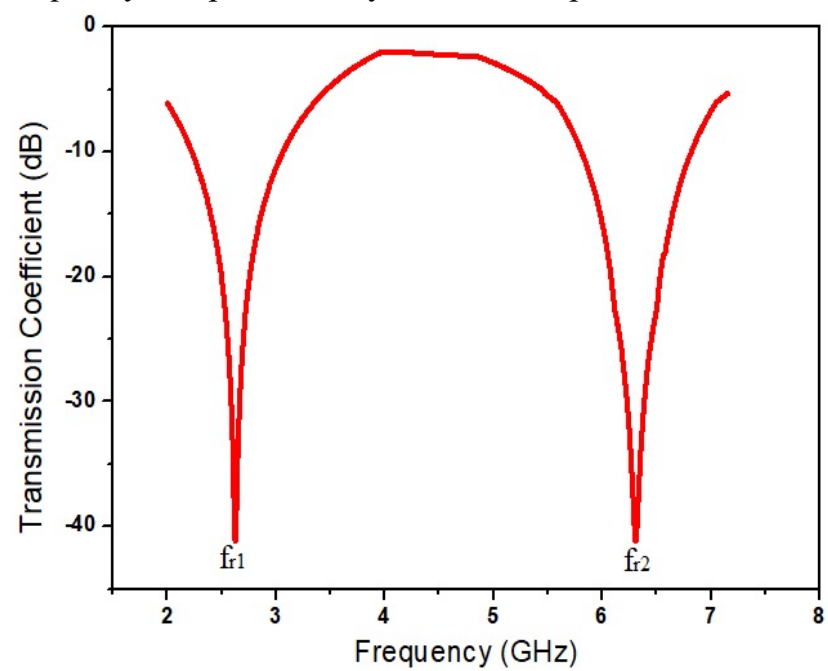

FIGURE 4: Frequency response of the DSLFSS depicting resonan frequencies.

\section{FSS BASED ANTENNA DESIGN METHODOLOGY}

The footprint of the design of a conventional rectangular patch radiator is illustrated in Figure 5(d). The dimensions are evaluated using transmission line model and are then optimized to get the designed results. The basic structural formulas used for designing the novel proposed patch radiator are extracted using transmission line model given in [1] and can be illustrated as:

Width (w) of the rectangular patch radiator is mathematically calculated as:

$\mathrm{w}=\frac{\mathrm{c}}{2 \mathrm{f}_{\mathrm{r}}} \sqrt{\frac{2}{\epsilon_{\mathrm{r}}+1}}$

In the above equation, the terms used may be defined as $\mathrm{w}$ $=$ width of the rectangular patch radiator, $\mathrm{c}=$ speed of light i.e. $3 \times 10^{8} \mathrm{~m} / \mathrm{sec}, \epsilon_{\mathrm{r}}=$ dielectric constant of the substrate on which patch is placed and $\mathrm{f}_{\mathrm{r}}=$ resonant frequency of operation. An important factor to be considered while constructing a rectangular patch antenna is the effective refractive index. Electromagnetic radiations emitting from a patch radiator migrate in the direction of the ground plane by using travelling mode of surrounding air but few amounts of radiations escape through the substrate (also known as fringing effect). So, to consider the effect of the propagation of waves across different mediums possessing different dielectric values, the value of the effective dielectric constant needs to be evaluated. The value of the effective dielectric constant $\left(\epsilon_{\text {eff }}\right)$ is calculated using the following equation [1]:

$\epsilon_{\mathrm{eff}}=\frac{\epsilon_{\mathrm{r}}+1}{2}+\frac{\epsilon_{\mathrm{r}}-1}{2}\left[1+12 \frac{\mathrm{t}}{\mathrm{w}}\right]^{-1 / 2}, \frac{\mathrm{w}}{\mathrm{t}}>1$

The thickness $(\mathrm{t})$ of the substrate has a substantial effect on the design of rectangular patch radiator as illustrated in (28). As discussed, the fringing effect has a substantial increase in overall electrical dimension of the antenna by the amount $(\Delta \mathrm{l})$ which is calculated as $[1]$ : 
$\frac{\Delta \mathrm{l}}{\mathrm{t}}=0.412 \frac{\left(\epsilon_{\mathrm{reff}}+0.3\right)\left(\frac{\mathrm{w}}{\mathrm{t}}+0.264\right)}{\left(\epsilon_{\mathrm{reff}}-0.258\right)\left(\frac{\mathrm{w}}{\mathrm{t}}+0.8\right)}$

The overall length ' 1 ' of the rectangular patch radiator is calculated as [1]:

$\mathrm{l}=\frac{\mathrm{c}}{2 \mathrm{f}_{\mathrm{r}} \sqrt{\epsilon_{\text {reff }}}}-2 \Delta \mathrm{l}$

Substrate dimensions can be calculated by extracting the dimensions of the ground plane as overall length and width of the substrate is equal to that of the ground plane. The value of the width of the ground $\left(\mathrm{w}_{\mathrm{g}}\right)$ and the length of the ground $\left(l_{\mathrm{g}}\right)$ is given as [1]:

$l_{\mathrm{g}}=6 \mathrm{t}+\mathrm{l}$

$\mathrm{w}_{\mathrm{g}}=6 \mathrm{t}+\mathrm{w}$

The formulas stated above are used to find the design dimensions of rectangular patch radiator. The dimensions calculated from the above formulae are optimized using parametric sweep for ensuring the functionality of the antenna in the desired frequency band of operation i.e. from $3.3 \mathrm{GHz}-4.2 \mathrm{GHz}$ as per $5 \mathrm{G}$ NR FR1 recommendation [7], [38]. Initially, a rectangular patch antenna is created with a full ground plane as depicted in Figure 5(a) and the results are reported. Further, bandwidth enhancement technique is utilized by reducing the length of the ground plane, as shown in Figure 5(b), and optimizing it to achieve the best response. For further enhancing the efficient bandwidth, as per the requirement for the $5 \mathrm{G}$ applications, a polygon slot is incorporated within the ground plane making it a partial slotted ground patch antenna radiator (PSGPAR), whose structure is depicted in Figure 5(c). The front view of the patch antenna radiator is visualized in Figure 5(d). The objective followed in this article focuses on enhancing the gain and directivity of a PAR by applying FSS as a superstrate for operation in the sub-6 GHz frequency range. Figure 5(e) shows the proposed high performance antenna schematic. As visualized, the proposed antenna design consists of two parts consisting of a DSLFSS based superstrate and a PAR as the feeding source. The single layer DSLFSS structure is utilized for getting a compact structure and is placed at a height of $\mathrm{H}$. The placement of FSS superstrate is in the direction of maximum radiation for improving the performance. The optimization of the proposed design is done using ANSYS HFSS software and the lateral dimension of the FSS superstrate layer created on the FR4 epoxy substrate of size $0.5 \lambda_{\text {mid }} \times 0.5 \lambda_{\text {mid'. }}$ The supply is given through SMA connector to DSLFSS based PAR and placed at a distance of $\left(\lambda_{\text {mid }}\right) / 30$ apart relative to the center of the dielectric. The proposed final design geometry is prepared by combining the two structures of antenna and DSLFSS defined in the earlier sections as illustrated in Figure 5(e). Both PAR and DSLFSS structure are placed on a stacked FR4 substrate of $1.6 \mathrm{~mm}$ of thickness. The antenna structure is excited with transmission line feed. DSLFSS structure designed in section III is meant to perform in sub- $6 \mathrm{GHz}$ bands of $5 \mathrm{G}$ frequency range and is inserted as a superstrate. To retain the radiation of the PAR in the sub-6 $\mathrm{GHz}$ bands of operation, the height $(\mathrm{H})$ between PAR and DSLFSS is optimized while all other measurements are kept same. The comparative analysis of the results retrieved for the reflection coefficient is formulated and is reported for the design iterations consisting of full ground, half ground and PSGRPA consisting of a polygon slot as depicted in Figure 6. It is indicated that as we progress through the iterations by varying the dimensions of the ground plane, an improvement is seen in the bandwidth of the designed antenna to cater $5 \mathrm{G}$ devices. Also, the past research and literature showed that for an increase in the value of the bandwidth, the gain decreases, therefore for an adequate value of gain it is not possible to get a high bandwidth of an antenna. Thus, to accommodate a large number of devices and for designing an efficient antenna it is required to get a feasible sufficiently high value of both the parameters. Further, size of the antenna is another main parameter that must be taken into account while optimizing the dimensions to achieve the parameters. The results achieved from all three iterations are reported and compared to get the best response. The dimensions reported to the parameters are conveyed in Table II, where $\lambda_{\text {mid' }}$ is the middle frequency wavelength within the operating band of $3.32 \mathrm{GHz}-4.2 \mathrm{GHz}$.

TABLE II. Design Parameters of the proposed PSGPAR.

\begin{tabular}{cc}
\hline \hline Parameter & Dimension \\
\hline Patch length $(1)$ & $0.475 \lambda_{\text {mid' }}$ \\
Patch width $(\mathrm{w})$ & $0.2 \lambda_{\text {mid' }}$ \\
\hline Arm length of the square substrate $\left(\mathrm{L}_{\mathrm{s}}\right)$ & $0.5 \lambda_{\text {mid' }}$ \\
Type of substrate & FR4 substrate \\
Thickness of the substrate $\left(\mathrm{t}_{\mathrm{s}}\right)$ & $0.02 \lambda_{\text {mid' }}$ \\
Feed line length $\left(\mathrm{f}_{\mathrm{l}}\right)$ & $0.02 \lambda_{\text {mid' }}$ \\
Feed line width $\left(\mathrm{f}_{\mathrm{w}}\right)$ & $0.01 \lambda_{\text {mid' }}$ \\
Length of the ground plane $\left(\mathrm{l}_{\mathrm{g}}\right)$ & $0.25 \lambda_{\text {mid' }}$ \\
Width of the ground plane $\left(\mathrm{w}_{\mathrm{g}}\right)$ & $0.5 \lambda_{\text {mid' }}$ \\
No. of polygon slot segments & $0.25 \lambda_{\text {mid }}$ \\
\hline
\end{tabular}

The values attained for the output performance parameters from the three design iterations are compared in Table III. It is clearly visible that as we incorporate the polygon slot inside the half ground, we get the optimum performance in terms of bandwidth but the values of the gain and the directivity decreases to some extent.

TABLE III. Output performance characteristics for the three iterations.

\begin{tabular}{cccc}
\hline \hline $\begin{array}{l}\text { Performance } \\
\text { characteristics }\end{array}$ & Full ground & $\begin{array}{c}\text { Half } \\
\text { ground }\end{array}$ & PSG (PAR) \\
\hline $\begin{array}{c}\text { Lower frequency } \\
\left(\mathrm{F}_{\mathrm{L}}\right)(\mathrm{GHz})\end{array}$ & $\mathrm{NR}$ & 3.75 & $3.30 \downarrow$ \\
Higher frequency & $\mathrm{NR}$ & 4.15 & $4.00 \downarrow$ \\
$\left(\mathrm{F}_{\mathrm{H}}\right)(\mathrm{GHz})$ & & & \\
Fractional B.W. & $\mathrm{NR}$ & $17.72 \%$ & $19.17 \%$ \\
Bandwidth $(\mathrm{MHz})$ & $\mathrm{NR}$ & 400 & $\mathbf{7 0 0} \uparrow$ \\
Gain $(\mathrm{dB})$ & $\mathrm{NR}$ & 4.12 & $2.44 \downarrow$ \\
Directivity $(\mathrm{dB})$ & $\mathrm{NR}$ & 5.21 & $3.21 \downarrow$
\end{tabular}


where NR stands for non radiating.

$\lg$

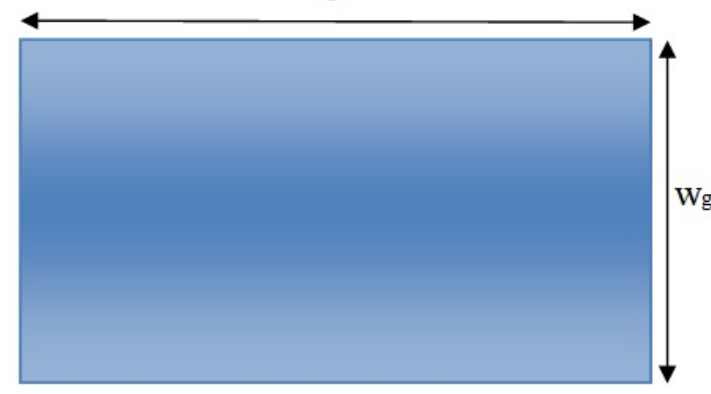

(a)

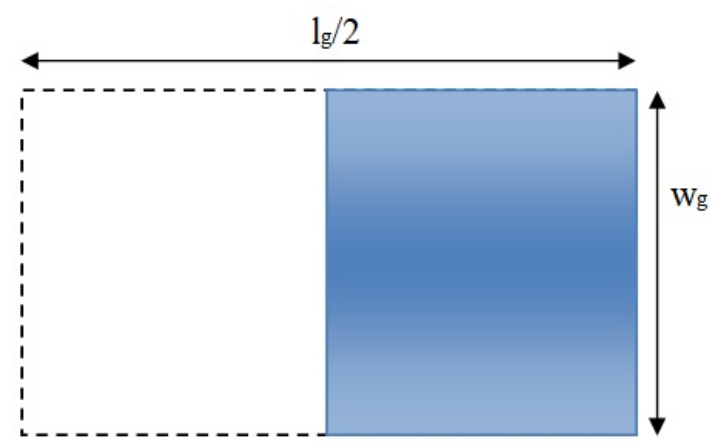

(b)

$\lg / 2$

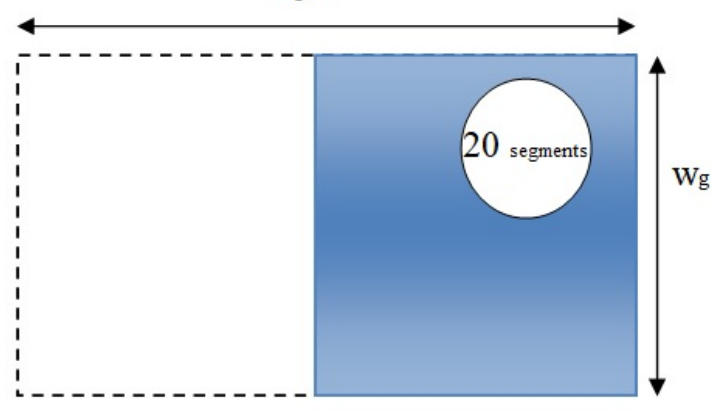

(c)

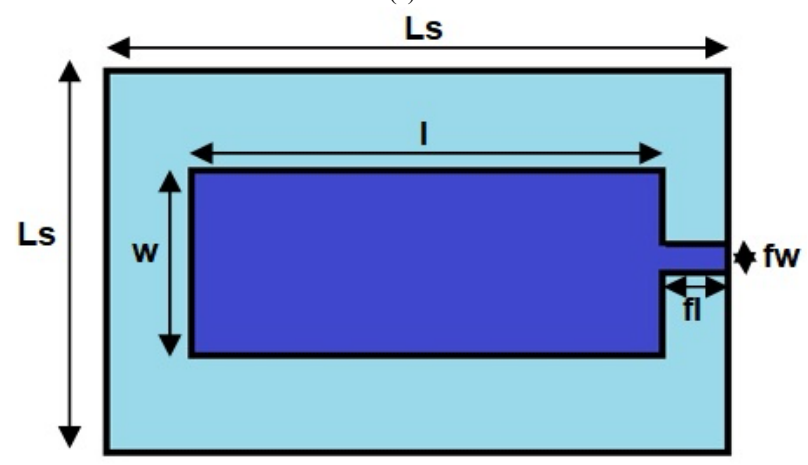

(d)

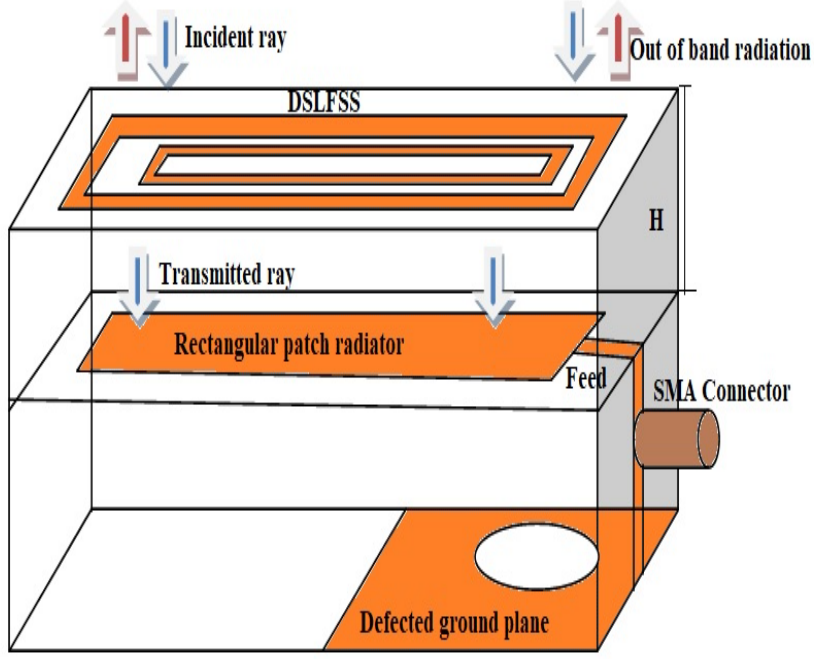

(e)

FIGURE 5: Configuration of the DSLFSS based PAR (a) full ground, (b) half ground, (c) partial slotted ground, (d) front view of patch antenna radiator, and (e) schematic diagram of the stacked antenna.

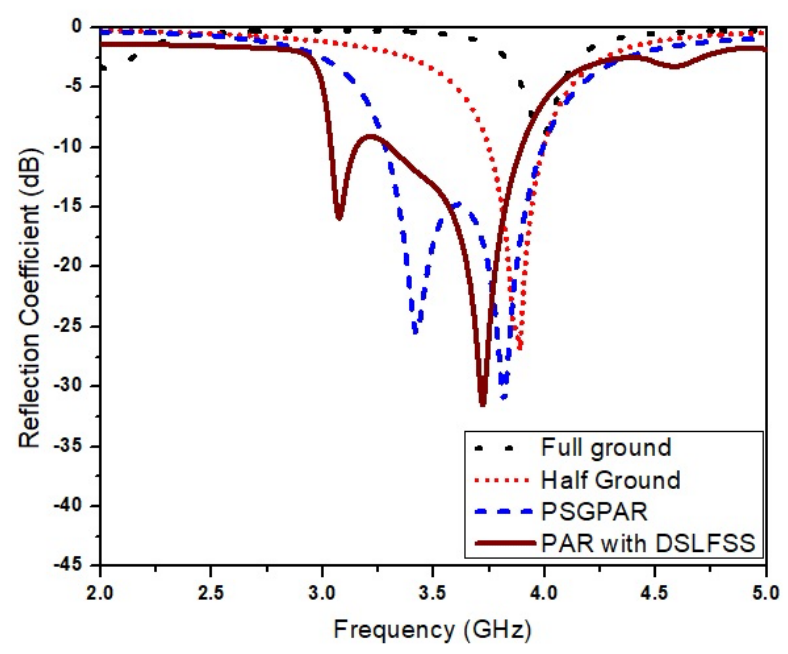

FIGURE 6: Comparative analysis of the design iterations for the reflection coefficient.

The simulated design is fabricated and visualized in Figure 7(a), Figure 7(b) and Figure 7(c) for PAR top view, bottom view and DSLFSS top view respectively. The stacked design is fabricated using a set of FR4 substrates and measurements are performed to validate our design for performance in the sub- $6 \mathrm{GHz}$ frequency spectrum. The designed prototypes of the DSLFSS and the combination of PAR with DSLFSS are illustrated in Figure 7(d). 


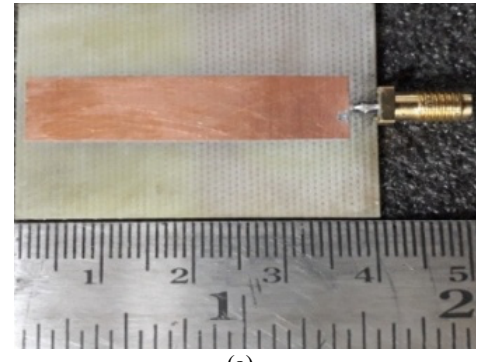

(a)

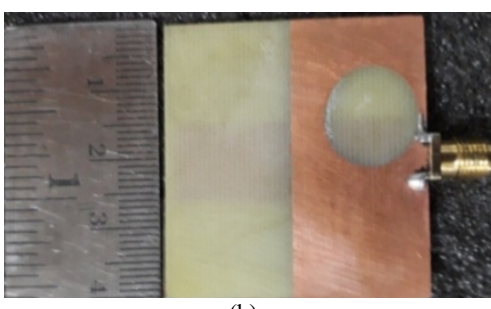

(b)

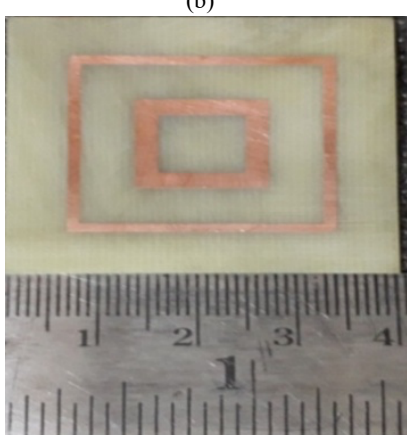

(c)

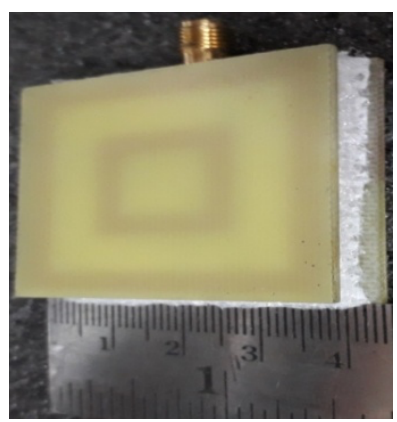

(d)

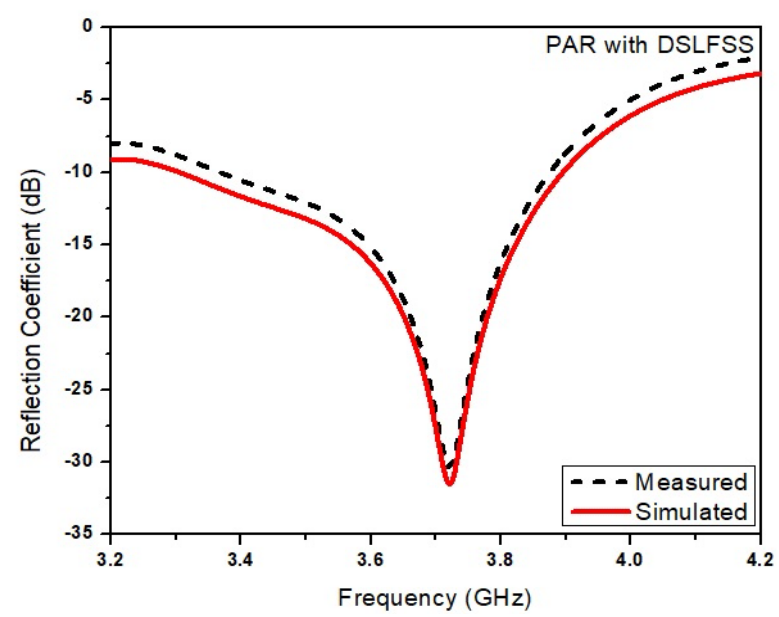

(a)

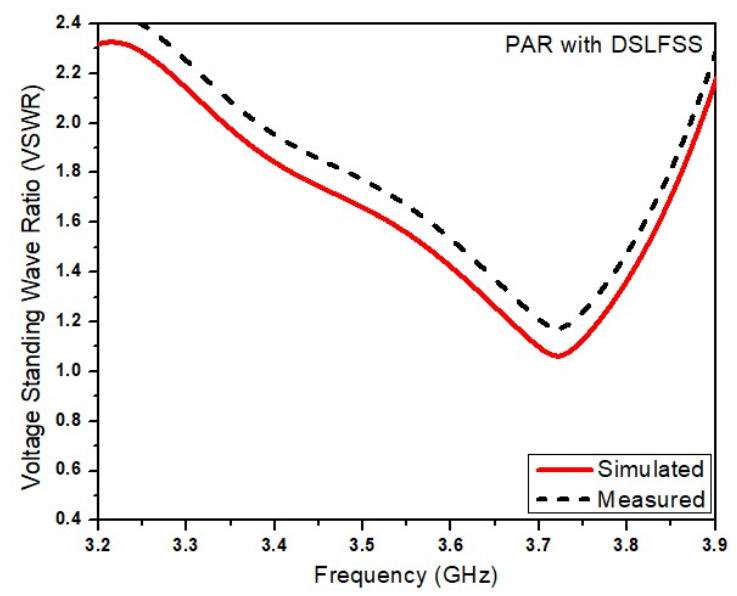

(b)

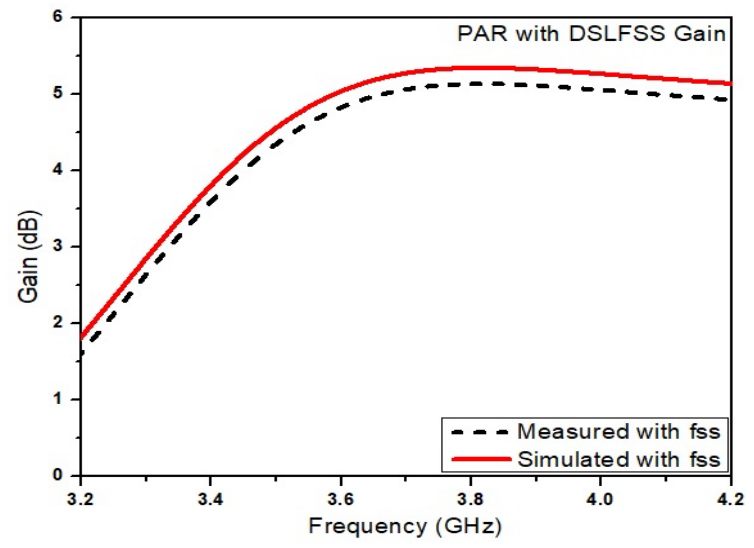

(c) gain and directivity retrieved from measurements are averaged and plotted in comparison to the simulation results as reported with in Figure 8 for the PAR design with DSLFSS. 


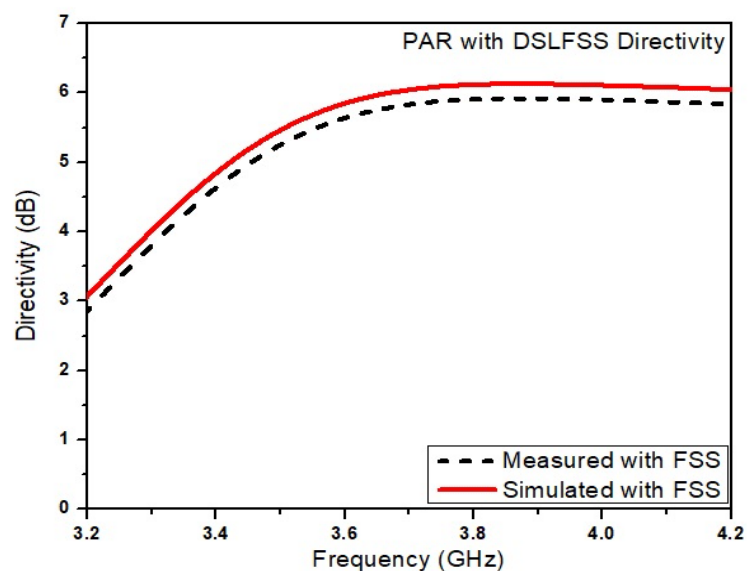

(d)

FIGURE 8: Comparative analysis of simulated and measured results of PAR with DSLFSS (a) reflection coefficient, (b) voltage standing wave ratio, (c) gain, and (d) directivity

The estimation of the resonance for the DSLFSS, in the broadside direction in the absence of a substrate, is based on ray tracing method as explained in [39]. The resonating length in terms of reflection phases and resonating frequencies can be extracted as:

$\mathrm{S}_{\text {air gap }}=\frac{\mathrm{P} \lambda}{2}+\left[\frac{\left.\psi_{\Gamma} \text { (frequency }\right)+\phi_{\Gamma}(\text { frequency })}{\pi}\right] \frac{\lambda}{4}$

where $\mathrm{P}=1,2,3 \ldots \ldots .$. any integer value, $\mathrm{S}_{\text {air gap denotes the }}$ spacing between the DSLFSS and the ground plane, $\psi_{\Gamma}$ denotes the reflection phase of the DSLFSS.

$\phi_{\Gamma}$ is the reflection phase of the ground plane which can be obtained as:

$\phi_{\Gamma} \Leftrightarrow<\frac{j \mathrm{Z}_{\mathrm{d}} \tan \left(\beta \mathrm{t}_{\mathrm{s}}\right)-\mathrm{Z}_{\mathrm{o}}}{\mathrm{j}_{\mathrm{d}} \tan \left(\beta \mathrm{t}_{\mathrm{s}}\right)+\mathrm{Z}_{\mathrm{o}}}=\pi-2 \tan ^{-1}\left(\mathrm{Z}_{\mathrm{d}} \tan \left(\beta \mathrm{t}_{\mathrm{s}}\right) / \mathrm{Z}_{\mathrm{o}}\right)$

Here $Z_{0}$ and $Z_{d}$ denote the values of characteristic impedance of the air and dielectric substrate respectively, $t_{s}$ is the effective dielectric thickness and $\beta$ denotes dielectric phase constant. The value of the directivity in the broad side direction is estimated as:

Directivity $=\frac{1+\Gamma}{1-\Gamma}$

The detailed information about the dimensions for the proposed stacked geometry of PAR with DSLFSS is described in Table IV as given below:

TABLE IV. Dimensions of the proposed PAR with DSLFSS.

\begin{tabular}{lr}
\hline \hline \multicolumn{1}{c}{ Parameters } & Dimension \\
\hline Length of the patch $(\mathrm{l})$ & $0.47 \lambda_{\text {mid' }}$ \\
Width of the patch $(\mathrm{w})$ & $0.2 \lambda_{\text {mid' }}$ \\
Arm length of the square substrate of antenna & \\
and DSLFSS $\left(\mathrm{L}_{\mathrm{s}}\right)$ & $0.5 \lambda_{\text {mid' }}$ \\
Type of substrate for antenna and DSLFSS & FR4 \\
Thickness of the antenna and DSLFSS & $0.02 \lambda_{\text {mid' }}$ \\
substrate $\left(\mathrm{t}_{\mathrm{s}}\right)$ & \\
Feed line length $\left(\mathrm{f}_{\mathrm{l}}\right)$ & \\
\end{tabular}

Feed line width $\left(f_{w}\right)$

$0.01 \lambda_{\text {mid }}$

Length of the ground plane $\left(1_{g}\right)$

$0.25 \lambda_{\text {mid' }}$

Width of the ground plane $\left(\mathrm{w}_{\mathrm{g}}\right)$

$0.5 \lambda_{\text {mid }}$ '

Polygon slot segments

20

Periodicity of DSLFSS (p)

$0.5 \lambda_{\text {mid }}$

$0.06 \lambda_{\text {mid }}$

$0.37 \lambda_{\text {mid }}$,

$0.05 \lambda_{\text {mid' }}$

$0.17 \lambda_{\text {mid }}$

Arm length of the inner loop of DSLFSS ( $\left.\mathrm{s}_{2}\right)$

$0.03 \lambda_{\text {mid' }}$

The measurements of the radiation patterns in the E-plane and H-plane, for the designs of the PAR with and without FSS superstrate, are shown in Figure 9. The model reveals a remarkable contrast in the main beam as well as inside lobes. Furthermore, the gain of the antenna was measured using the comparing gain method. It is clearly extracted that as compared to the PAR, the proposed design exhibits a gain enhancement of $3.06 \mathrm{~dB}$ with a single FSS superstrate. The design structure demonstrated dumbbell shaped omnidirectional patterns in E-plane and H-plane.

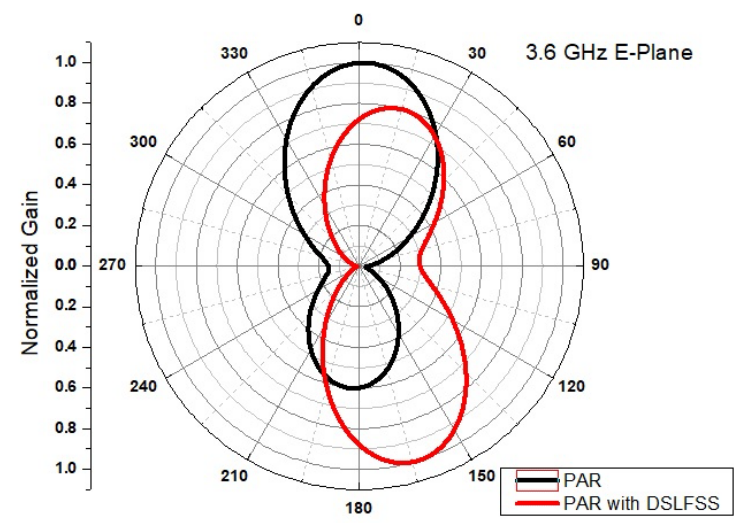

(a)

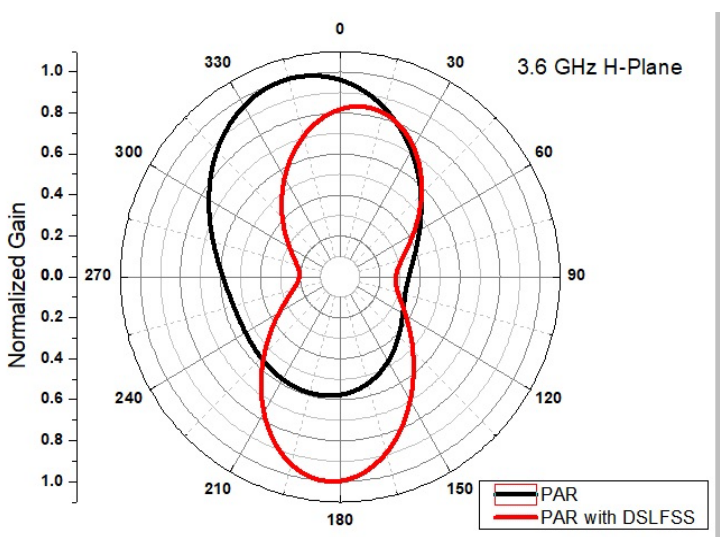

(b) 
FIGURE 9: Radiation patterns of the PAR with and without DSLFSS superstrate, (a) E-plane, and (b) H-plane.

The comparative analysis of the both the proposed designs comprising of PAR and DSLFSS based PAR are elaborated in Table V.

TABLE V. Performance comparison of PAR with and without DSLFSS.

\begin{tabular}{ccc}
\hline \hline Parameter & $\begin{array}{c}\text { PAR without } \\
\text { DSLFSS }\end{array}$ & $\begin{array}{c}\text { PAR with } \\
\text { DSLFSS }\end{array}$ \\
\hline Lower frequency $\left(\mathrm{f}_{\mathrm{r} 1}\right)$ & 3.30 & 3.26 \\
$(\mathrm{GHz})$ & & \\
Higher frequency $\left(\mathrm{f}_{\mathrm{r} 2}\right)$ & 4.00 & 3.95 \\
$(\mathrm{GHz})$ & $19.17 \%$ & $19.14 \%$ \\
Fractional bandwidth & 700 & 690 \\
Bandwidth $(\mathrm{MHz})$ & 2.44 & 5.5 \\
Peak Gain $(\mathrm{dB})$ & 3.21 & 6.2 \\
Peak Directivity $(\mathrm{dB})$ & & \\
\hline
\end{tabular}

An increase in the bandwidth along with a rise in the values of gain and directivity is indicated in Table V. The data reported in this paper makes our design suitable for high performance wideband applications in sub-6 GHz $5 \mathrm{G}$ spectrum using a compact structure. The validation of the performance characteristics is completed by measuring the output performances of the fabricated designed stacked antenna as reported in Table VI.

TABLE VI. Simulated and measured results of PAR with DSLFSS.

\begin{tabular}{lcc}
\hline \hline \multicolumn{1}{c}{ Antenna parameter } & $\begin{array}{c}\text { Simulated value } \\
\text { (Stacked design) }\end{array}$ & $\begin{array}{c}\text { Measured value } \\
\text { (Stacked design) }\end{array}$ \\
\hline Lower frequency $\left(\mathrm{f}_{\mathrm{r} 1}\right)$ & 3.26 & 3.27 \\
$(\mathrm{GHz})$ & 3.95 & 3.93 \\
Higher frequency $\left(\mathrm{f}_{\mathrm{r} 2}\right)$ & & \\
$(\mathrm{GHz})$ & $19.14 \%$ & $18.33 \%$ \\
Fractional bandwidth & 690 & 660 \\
Bandwidth (MHz) & 5.5 & 5.3 \\
Peak Gain (dB) & 6.2 & 5.9 \\
Peak Directivity $(\mathrm{dB})$ & & \\
\hline
\end{tabular}

Hence, the dual layer stacked geometry of PAR with DSLFSS holds the advantages of being compact and it exhibits better performance for the wideband applications in sub-6 GHz, which is the need of the hour. The importance of our proposed design as compared to other related research is elaborated in Table VII. It is clearly visible that the design proposed is exhibiting best performance improvement in terms of fractional bandwidth and gain along with maintaining compactness of the design as compared to others.

TABLE VII. Performance comparison with earlier investigated designs.

\begin{tabular}{|c|c|c|c|c|}
\hline Ref & $\begin{array}{l}\text { Patch } \\
\text { radiator } \\
\text { size }\end{array}$ & $\begin{array}{c}\text { Frequenc } \\
\text { y band } \\
(\mathrm{GHz})\end{array}$ & $\begin{array}{l}\text { Fractional } \\
\text { bandwidth }\end{array}$ & $\begin{array}{l}\text { Peak } \\
\text { gain } \\
(\mathrm{dBi}) \\
\end{array}$ \\
\hline $\begin{array}{l}\text { Chen \& } \\
\text { Tao [40] }\end{array}$ & $\begin{array}{c}0.61 \lambda_{\text {mid }} \times \\
0.42 \lambda_{\text {mid }} \times\end{array}$ & 2.45 & $5.51 \%$ & 4.92 \\
\hline $\begin{array}{c}\text { Rishishwar } \\
\& \\
\text { Shrivastava } \\
{[41]}\end{array}$ & $\begin{array}{c}0.22 \lambda_{\text {mid }} \times \\
0.18 \lambda_{\text {mid }}\end{array}$ & $2.2-2.44$ & $10.34 \%$ & 5.2 \\
\hline $\begin{array}{c}\text { Kakhki et. } \\
\text { al. [42] }\end{array}$ & $\begin{array}{c}1.87 \lambda_{\text {mid }} \times \\
0.13 \lambda_{\text {mid' }} \times\end{array}$ & $27.5-28.4$ & $3.22 \%$ & 5 \\
\hline $\begin{array}{c}\text { Filho et. al. } \\
\text { [43] }\end{array}$ & $\begin{array}{c}0.72 \lambda_{\text {mid }} \times \\
0.37 \lambda_{\text {mid }}\end{array}$ & $2.4-2.7$ & $5.18 \%$ & 4.46 \\
\hline $\begin{array}{l}\text { Sugumaran } \\
\text { et. al. [44] }\end{array}$ & $\begin{array}{c}0.41 \lambda_{\text {mid }} \times \\
0.33 \lambda_{\text {mid' }}\end{array}$ & $2.3-2.66$ & $14.51 \%$ & 4.78 \\
\hline $\begin{array}{l}\text { Our } \\
\text { proposed } \\
\text { design }\end{array}$ & $\begin{array}{c}0.47 \lambda_{\text {mid }}, \times \\
0.20 \lambda_{\text {mid }},\end{array}$ & $3.2-4.2$ & $19.14 \%$ & 5.5 \\
\hline
\end{tabular}

\section{CONCLUSION}

In this article, a simple and effective synthesis technique for designing high performance printed patch antenna radiator is presented by incorporating a double square loop frequency selective surface. The design of a wideband antenna is accomplished by incorporating a twenty-segment polygon slot in the partial half ground surface. Consequently, a novel synthesis technique for designing of double square loop frequency selective surface in the $\mathrm{n} 77$ and $\mathrm{n} 78$ bands of the sub-6 GHz 5G spectrum is introduced. The designed double square loop frequency selective surface is substituted as a superstrate on the patch antenna radiator. The stacked design geometry is simulated and results are validated by performing measurements of the fabricated prototype. It is clearly shown that an enhancement in gain and directivity is seen while maintaining sufficient bandwidth. The bandwidth of $690 \mathrm{MHz}$ is achieved with gain and directivity of $5.5 \mathrm{dBi}$ and $6.2 \mathrm{dBi}$, respectively. Incorporation of frequency selective surface helps to get the increse in gain and directivity of $3.06 \mathrm{dBi}$ and $2.99 \mathrm{dBi}$, respectively along with attaining fractional bandwidth of $19.14 \%$. The proposed compact and high gain antenna is suitable for sub-6 GHz 5G wideband communications.

\section{REFERENCES}

1. R. Garg, P. Bhartia, I. J. Bahl, and A. Ittipiboon, "Microstrip Antenna Design Handbook”, Artech House, Boston, 2001.

2. E. K. I. Hamad and N. Mahmoud, "Compact Tri-Band Notched Characteristics UWB Antenna for WiMAX, WLAN and X-Band Applications", $A E M$, vol. 6, no. 2, pp. 53-58, 2017. 
3. N. Panwar, S. Sharma, A. K. Singh, "A survey on 5G: The next generation of mobile communication", Phys. Commun., vol. 18, pp. 64-84, 2016

4. M. J. Marcus, "5G and IMT for 2020 and beyond [spectrum policy and regulatory issues]", IEEE Wireless Communications, vol.22, pp. $2-3,2015$.

5. T. S. Rappaport, S. Sun, R. Mayzus, H. Zhao, Y. Azar, K. Wang, G. N. Wong, J. K. Schulz, M. Samimi and F. Gutierrez, "Millimeter wave mobile communications for 5G cellular: it will work!", IEEE Access, vol. 1, pp. 335-349, 2013.

6. Z. An and M. He, "A simple planar antenna for sub-6 $\mathrm{GHz}$ applications in 5G mobile terminals", Applied Computational Electromagnetics Society Journal, vol. 35, pp. 10-15, 2020.

7. A. Kapoor, R. Mishra, and P. Kumar, "Compact wideband-printed antenna for Sub-6-GHz fifth-generation applications," International Journal of Smart Sensing and Intelligent Systems, vol. 13, no. 1, pp. 1-10, 2020.

8. B. A. Munk, "Frequency Selective Surfaces Theory and Design", New York: Wiley,2000.

9. A. Kapoor, R. Mishra, P. Kumar, "Novel Wideband Frequency Selective Surface Based Spatial Filters for Sub-6 GHz 5G devices", In: The proceedings of IEEE International Conference on Nascent Technologies in Engineering, India, 2021.

10. A. Kapoor, R. Mishra and P. Kumar, "Slotted Wideband Frequency Selective Reflectors for Sub-6 GHz 5G Devices," 2021 International Conference on Computing, Communication, and Intelligent Systems (ICCCIS), pp. 786-791, 2021.

11. M. Li, A. Al-Joumayly Mudar, and N. Behdad, "Broadband TrueTime-Delay Microwave Lenses Based on Miniaturized Element Frequency Selective Surfaces," IEEE Transactions on Antennas and Propagation, vol. 61, no. 3, pp. 1166- 1179, 2013.

12. K. K. Varikuntla and R. Singarav, "Review on Design of Frequency Selective Surfaces based on Substrate Integrated Waveguide Technology", $A E M$, vol. 7, no. 5, pp. 101-110, Nov. 2018.

13. F. Costa, and A. Monorchio, "A frequency Selective Radome with Wideband Absorbing Properties," IEEE Transactions on Antennas and Propagation, vol. 6, no. 6, pp. 2740-2747, 2012.

14. E. GhasemiMizuji, A. Abdolali, and I. Derafshi, "Analytical Solution for Elliptical Cloaks Based on The Frequency Selective Surface", $A E M$, vol. 3, no. 2, pp. 16-20, Jan. 2015.

15. M. Mahmoodi and K. M. Donnell, "Performance Metrics for Frequency Selective Surface-Based Sensor," IEEE Sensor Letter, vol. 1 , no. 6,2017

16. E. Kinzel, "Design of a Frequency-Selective Surface Strain Sensor," IEEE Antennas and Propagation Society International Symposium (APSURSI), pp. 2074-2075, 2014.

17. S. Jang, B. Kang, and J. Kim, "Frequency Selective Surface Based Passive Wireless Sensor for Structural Health Monitoring," Smart Materials and Structures, vol. 22, no. 2, 2013.

18. D. F. Pieper, and K. M. Donnell, "Application of Frequency Selective Surfaces for Inspection of Layered Structures," Instrumentation and Measurement Technology Conference (I2MTC), pp. 1204-1209, 2015.

19. M. Mahmoodi, and K. M. Donnell, "Active Frequency Selective Surface for Strain Sensing," IEEE Antennas and Propagation Society International Symposium (APSURSI), pp. 679-680, 2017.

20. F. A. Tahir, T. Arshad, S. Ullah, J. A Flint., "A novel FSS for gain enhancement of printed antennas in UWB frequency spectrum", Microw Opt Technol Lett., vol. 59, pp. 2698-2704, 2017.

21. P. Zhao, Y. Zhang, R. Sun, W. Zhao, Y. Hu, G. Wang, "Design of a Novel Miniaturized Frequency Selective Surface Based on 2.5Dimensional Jerusalem Cross for 5G Applications", Wireless Communications and Mobile Computing, vol. 2018, Article ID 3485208, 6 pages, 2018.

22. P. Das, S. Biswas, S. S. Ridhwaan, R. Ray, D. Ghosh and D. Sarkar, "Design and Analysis of Frequency Selective Surface Integrated Circular Disc Antenna," 2018 2nd International Conference on Electronics, Materials Engineering \& Nano-Technology (IEMENTech), Kolkata, pp. 1-5, 2018.

23. Sarika, M. R. Tripathy, and D. Ronnow, "A Wideband Frequency Selective Surface Reflector for 4G/X-Band/Ku-Band," Progress In Electromagnetics Research C, vol. 81, pp. 151-159, 2018
24. U. Farooq, A. Iftikhar, M. F. Shafique, M. J. Mughal, "A Miniaturized and Polarization Insensitive FSS and CFSS for Dual Band WLAN Applications", AEU - International Journal of Electronics and Communications, vol.105, pp. 124-134, 2019.

25. R. Adeline Mellita, D. S. Chandu, S. S. Karthikeyan, P. Damodharan, "A miniaturized wideband frequency selective surface with interconnected cell structure", AEU - International Journal of Electronics and Communications, vol. 120, pp. 153-196, 2020.

26. H. Y. Chen and Y. Tao, "Antenna gain and bandwidth enhancement using frequency selective surface with double rectangular ring elements," Proceedings of the 9th International Symposium on Antennas, Propagation and EM Theory, Guangzhou, pp. 271-274, 2010 .

27. K. Mondal, "Bandwidth and gain enhancement of microstrip antenna by frequency selective surface for WLAN, WiMAX applications", Sādhanā , vol. 44, no. 233, 2019.

28. E. M. F. Fernandes, M. W. B. Silva, L. D. Silva Briggs, A. L. P. D S. Campos, H. X. D. Araújo, I. R. S. Casella, C. E. Capovilla, V. P. R. Magri Souza, L. J. de Matos, "2.4-5.8 GHz dual-band patch antenna with FSS reflector for radiation parameters enhancement", AEU - International Journal of Electronics and Communications, vol. 108 , pp. 235-241, 2019.

29. O. T. Kucuksari, A. Kocakaya, S. Çimen, G. Çakır, "High constant gain modified antipodal Vivaldi antenna incorporated with a phase compensation lens and a frequency selective surface", $A E U$ International Journal of Electronics and Communications, vol. 113 pp. 152975,2020

30. A. Swetha, K. Rama Naidu, "Gain Enhancement of an UWB Antenna Based on a FSS Reflector for Broadband Applications," Progress In Electromagnetics Research C, vol. 99, pp. 193-208, 2020 .

31. N. Kushwaha, R. Kumar, "Gain enhancement of wideband circularly polarized antenna using FSS," International Journal of Microwave and Wireless Technologies, vol. 9, no. 3, pp. 697-703, 2017.

32. E. Moharamzadeh, "Radiation Characteristic Improvement of XBand Slot Antenna Using New Multiband Frequency-Selective Surface", International Journal of Antennas and Propagation, vol. 2014, 9 pages, 2014.

33. R. Agarwal, M. Bohner, A. Domoshnitsky, et al., "Floquet theory and stability of nonlinear integro-differential equations", Acta Math Hung, vol. 109, pp.305-330, 2005.

34. N. Marcuwitz, "Waveguide Handbook”, McGraw-Hill, 1st Edition, New York, 1951

35. K. R. Jha, G. Singh, R. Jyoti, "A simple synthesis technique of single square loop frequency selective surface", Progress in Electromagnetic Research B, vol. 45, pp. 165-185, 2013.

36. A. E. Yilmaz, and M. Kuzuoglu, "Design of the square loop frequency selective surfaces with particle swarm optimization via the equivalent circuit model," Radioengineering, vol. 18, no. 2, pp. 95-102, 2009.

37. M. J. Archer, "Wave reactance of thin planar strip gratings", International Journal of Electronics, vol. 58, pp. 187 - 230, 1985.

38. A. Tikhomirov, E. Omelyanchuk and A. Semenova, "Recommended 5G frequency bands evaluation," Systems of Signals Generating and Processing in the Field of on Board Communications, Moscow, Russia, pp. 1-5, 2018

39. A. Foroozesh and L. Shafai, "Investigation Into the Effects of the Patch-Type FSS Superstrate on the High-Gain Cavity Resonance Antenna Design," IEEE Transactions on Antennas and Propagation, vol. 58, no. 2, pp. 258-270, 2010.

40. H. Chen, Y. Tao, "Bandwidth enhancement of a u-slot patch antenna using dual band frequency-selective surface with double rectangular ring elements," Microwave Opt Technol Lett., vol.53, no. 7, pp.1547-53, 2011

41. D. Rishishwar, L. Shrivastava, "Rectangular microstrip patch antenna with FSS and slotted patch to enhance bandwidth at 2.4 GHz for WLAN applications", Int. J Technol Enhance Emerg Eng Res, vol. 2, no. 4, pp. 59-62, 2014.

42. M. B. Kakhki, M. Mantash and T. A. Denidni, "Gain Enhancement of Colinear Antenna-Array Using a Frequency Selective Surface," 2018 18th International Symposium on Antenna Technology and Applied Electromagnetics (ANTEM), pp. 1-2, 2018. 
43. A. Filho, A. Valdez, A. L. P. S. Campos, "Performance optimization of microstrip antenna array using frequency selective surfaces", J. Microw. Optoelectron. Electromagn. Appl., vol.13, no.1, pp. 31-46. 2014.

44. B. Sugumaran, R. Balasubramanian, "Design and Analysis of Fractal Based Monopole Antenna Backed with Modified Jerusalem Cross Frequency Selective Surface for Wireless Personal Area Communications", Mobile Netw Appl., vol. 25, pp.2092-2101, 2020. 